\title{
GESTÃO ESCOLAR: UM OLHAR SOBRE O DISCURSO DOS DOCENTES
}

Elisangela Aparecida Bulla Ikeshojii ${ }^{1}$ Adriana Aparecida de Lima Terçariol ${ }^{2}$.

Instituto Federal de Educação Ciência e Tecnologia de São Paulo - IFSP ${ }^{1}$, Universidade Nove de Julho - UNINOVE, São Paulo, SP. E-mail: elisangela.bulla@gmail.com.

\section{RESUMO}

O objetivo deste estudo foi identificar e analisar como os docentes percebem a gestão escolar no contexto da instituição pública federal de ensino profissional e tecnológico. A metodologia adotada para realização deste estudo utilizou-se dos conhecimentos produzidos nos textos obtidos após a realização do levantamento de publicações científicas, desenvolvidas no Brasil nos últimos 16 anos, entre 2000 e 2015, na base de dados do Scielo (Scientific Eletronic Library Online) e na base de dados do IBICT (Instituto Brasileiro de Informações em Ciência e Tecnologia). Utilizouse ainda de entrevista semiestruturada, realizada com 15 docentes, como instrumento para coleta de dados, cuja organização e análise foi realizada, a partir da técnica do Discurso do Sujeito Coletivo (DSC). Os principais resultados evidenciaram que na percepção dos docentes a gestão escolar precisa ser organizada de acordo com o trabalho pedagógico e com os interesses da comunidade escolar.

PALAVRAS-CHAVE: Gestão Escolar, Planejamento Pedagógico, Princípios da Gestão Escolar, Desafios.

\section{SCHOOL MANAGEMENT: A GLANCE OVER THE SPEECH OF TEACHERS}

\begin{abstract}
The aim of this study was to identify and analyze how the teachers perceive the school management in the context of a federal public institution of professional and technological teaching. The methodology adopted to conduct this study is grounded in the knowledge present in the literature obtained after a survey of scientific publications, developed in Brazil in the last 16 years, between 2000 and 2015, in the Scielo database (Scientific Electronic Library Online) and, in the IBICT database (Brazilian Institute of Information in Science and Technology). It was used also semi structured interview with 15 teachers, as data collection instrument, whose organization and analysis were performed with the technique of Discourse of Collective Subject. The main results have showed that, in the perception of teachers, the school management must be organized in accordance with the pedagogical work and with the interests of the school community.
\end{abstract}

KEYWORDS: School Management, Pedagogical Planning, Principles of School Management, Challenges. 


\section{INTRODUÇÃO}

A gestão escolar, ao ser compreendida como prática administrativa e pedagógica, em que os instrumentos da administração servem para organizar o trabalho pedagógico, deve contribuir para planejar as ações que vão ao encontro dos interesses da comunidade escolar. Entende-se que a comunidade escolar tem seus anseios e necessidades, bem como suas potencialidades que são mobilizadas quando participam de forma coletiva. Essa participação precisa ocorrer não somente por obrigação ou imposição; ela requer em contrapartida o acolhimento, reconhecimento, feedback das ações oriundas de suas colaborações. Nesse sentido, o objetivo deste estudo foi identificar e analisar como os docentes percebem a gestão escolar no contexto da instituição pública federal de ensino profissional e tecnológico.

\section{METODOLOGIA}

Este trabalho é fruto de levantamento das publicações disponibilizadas na base de dados do Scielo (Scientific Eletronic Library Online) e na base de dados IBICT (Instituto Brasileiro de Informações em Ciência e Tecnologia), produzidas nos últimos 16 anos, entre 2000 e 2015. Na base de dados Scielo, dos cinquenta e seis artigos escolheram-se três artigos tendo por base que no resumo houve um viés com o objetivo desta pesquisa. Na base de dados do IBICT, dentre as teses e dissertações que versam a respeito do tema, dos sessenta e seis trabalhos disponibilizados, seis foram selecionados.

Fizeram parte deste estudo 15 docentes de uma instituição pública federal de ensino profissional e tecnológico do interior de São Paulo. Pesquisa realizada no 1 semestre de 2015 após aprovação pelo Comitê de Ética e Pesquisa da Unoeste sob número 2317 e CAAE no 37780414.6.0000.5515 integrada a dissertação de mestrado em educação intitulada "Gestão na perspectiva do diretor e de docentes: estudo de caso em uma instituição pública de ensino profissional e tecnológico".

Para a coleta de dados, utilizou-se como instrumento a entrevista semiestruturada. Após coleta, seleção e organização dos dados, realizou-se a análise a partir da técnica do Discurso do Sujeito Coletivo (DSC). A medida que os DSC vão sendo construídos, apresentam-se como se fossem um discurso individual, caracterizando-se assim como um sistema de interpretação da realidade pelos participantes e suas relações com o contexto social, elucidando comportamentos e práticas (LEFÈVRE; CRESTANA; CORNETTA, 2003). A seguir, apresenta-se cada uma das categorias e trechos de seus respectivos DSC que desencadeiam a discussão, articulando teorias e estudos já realizados na área.

\section{GESTÃO ESCOLAR COMO PRÁTICA ADMINISTRATIVA E PEDAGÓGICA}

Os aspectos administrativos são importantes instrumentos para organizar o trabalho escolar, portanto, direcionados para atender ao processo de ensino e aprendizagem, ou seja, as questões fundamentalmente pedagógicas (PARO, 2010). Todavia o processo de ensino e aprendizagem não é compreendido pelos docentes como aspectos da gestão escolar, segundo se evidencia a seguir:

Excerto - DSC2: Gestão é tudo que não envolve a parte diretamente de ensino, que eu digo de ir lá na lousa, mas todo esse suporte que a gente tem que ter para dar a aula, para limpar a escola, é gestão. É a parte do desenvolvimento da escola que preza pelo andamento técnico, pelo andamento de estruturas, que não envolva sala de aula, diretamente no sentido de dar a matéria. 
No entanto, as falas vêm ao encontro do que apresenta Hojas (2015, p. 323), sobre a "importação da gerência empresarial para as escolas e os sistemas de ensino". Ultrapassar essa concepção é necessário, pois entende-se que é intrínseco ao diretor da escola estar focado, essencialmente, com o processo de ensino e aprendizagem, sendo as atividades administrativas e gerencialistas, também burocráticas, apenas instrumentos para desenvolver e realizar o seu trabalho (SOUZA; GOUVEIA, 2010). Mas outros docentes compreendem que as atividades pedagógicas e administrativas não devem ser vistas como mutuamente exclusivas; pelo contrário, o administrativo e o pedagógico devem coexistir.

Excerto - DSC1: Não só o processo de ensino, mas toda a parte dela, como ela tem que funcionar, planejamento, execução, comunicação. Como é que são as melhores práticas de ensino, como é que estão as práticas de ensino, como é que os nossos docentes estão dando aula, como é que os alunos estão absorvendo esse conteúdo. O meio onde você ingressa os alunos diante de uma experiência de ensino.

Embora não seja fácil essa compreensão, Formiga (2007) em sua pesquisa demonstra que existem dificuldades dos profissionais da educação, no caso, diretores e supervisores escolares em apreender o pedagógico e a sua relação com o administrativo. Isso resulta da dificuldade de compreender que o diretor tem função política pedagógica e educacional, e os instrumentos da administração contribuem para o "fazer pedagógico".

\section{PARTICIPAÇÃO NO PLANEJAMENTO PEDAGÓGICO}

O planejamento como processo empregado na administração é inerente à gestão escolar. Essa é uma ação primeira que deve ocorrer para organizar toda atividade educacional, ou seja, é a escola na sua completude em função do trabalho pedagógico. Isso, porque o planejamento organiza e dá sentido e unidade ao trabalho, norteia as ações e contribui para minimizar tantos erros que causam muitos prejuízos à educação. Alguns docentes tratam da questão do planejamento pedagógico como obrigação.

Excerto - DSC3: Sempre no começo do semestre tem planejamento escolar. Eu participo do planejamento do início do semestre, de forma a seguir o regimento escolar, que pede que eu participe de reuniões com meus pares. [...]. Eu participo só do que é obrigação. Na verdade eu não faço nada específico, mas acompanho as reuniões, as participações coletivas, e não tenho uma atuação diferenciada, apenas o que a comunidade pratica, sempre estou participando.

E outros docentes com um discurso diferenciado sinalizam compromisso quando se referem à participação no planejamento pedagógico:

Excerto - DSC4: Participo das outras comissões, dando sugestões, opiniões a respeito de vários contextos. Na elaboração e melhoria dos planos pedagógicos dos cursos. Tenho meus planos de ensino que estão prontos, na data.

O planejamento pedagógico que ocorre na instituição, somente no início do semestre, é para elaborar os planos de aula, plano de ensino e organizar o horário dos docentes. Todavia a 
identidade da escola passa pelo planejamento educacional que se desdobra no projeto políticopedagógico. Esse documento retrata a identidade da escola e está em construção, segundo apresenta o discurso abaixo:

Excerto - DSC4: Na elaboração do projeto político pedagógico (PPP) é a nossa identidade e nas reuniões. Esse comprometimento meu é uma característica da minha pessoa, se eu não fizer de uma forma com comprometimento para atingir o objetivo que é fazer o aluno entender o que eu tenho que passar pra ele, caso contrário, não vejo muito sentido.

O projeto político-pedagógico é um documento a ser elaborado pelos estabelecimentos de ensino, conforme menciona o artigo 12 da Lei de Diretrizes e Bases da Educação Nacional (LDB) no 9.394 (BRASIL, 1996). É um projeto que deve ser elaborado de forma participativa e colaborativa, contando com apoio da comunidade escolar - docentes, funcionários, estudantes e pais - pois ele dá a identidade à instituição educacional.

\section{ESTÍMULO NA EXECUÇÃO DAS AÇÕES PEDAGÓGICAS}

O diretor tem o papel fundamental de contribuir para estimular o desenvolvimento de todo o planejamento escolar, assim como estimular as ações pedagógicas. Pontua Assunção (2004, p. 10) com sua pesquisa que "[...] a atuação pedagógica encontra-se intimamente ligada à forma como o diretor organiza a escola." Segundo Abdian, Oliveira, Jesus (2013) e Silva, Leme (2009), nos diferentes aspectos do contexto escolar - humanos, administrativos e pedagógicos - o diretor tem papel fundamental para assegurar a unidade e a implementação de todo o planejamento escolar. Deve agir de maneira que os docentes conheçam todas as atividades desenvolvidas na escola, o que parece não ocorrer, segundo discurso dos docentes.

Excerto - DSC5: Talvez exista alguma forma de apoio para o setor sócio pedagógico, por exemplo, ou para a gerência educacional, que faça com que chegue até a gente este tipo de trabalho. Mas eu não sei se é exatamente esse trabalho da direção que vem esse apoio, ou se vem mesmo dos gerentes, da parte pedagógica mesmo da instituição.

É possível perceber também que no contexto investigado não ocorre estímulo por parte do diretor no que se relaciona à execução das ações pedagógicas.

Excerto - DSC6: Às vezes o foco é para uma gestão administrativa, em que o ensino, às vezes fica num segundo plano. Cabe a mim enquanto docente cobrar isto e participar, fazer a minha parte, mas tem hora que a gente fica de mãos atadas, lutando contra a maré, falando de algo importante que para a maioria das pessoas não é importante.

Ainda que, para esses docentes não exista estímulo por parte do diretor, os docentes que escolhem ou optam pela profissão de docente precisam compreender que "para ser sujeito em qualquer profissão é inegável a necessidade de se deter o conhecimento sobre a mesma e o seu campo de atuação." (IGREJA, 2008, p. 92). No entanto, ainda que segundo alguns docentes a falta estímulo por parte do diretor ocorra, outros docentes não veem dessa maneira, conforme o discurso a seguir:

Excerto - DSC5: Estimula sim, quanto às ações pedagógicas são no sentido de dar aula direito. Ele interfere no ambiente de sala de aula, ele esta presente quando ele oferece melhor ou pior condições de ensino, estrutura. 
A postura de um diretor pró ativo, aberto ao diálogo e à escuta contribui para que os objetivos educacionais sejam atingidos. No entanto, segundo o discurso dos docentes tal aspecto parece não acontecer.

Excerto - DSC6: Não se vê uma pessoa pró ativa que busca resolver os interesses locais do campus, porque o gestor ele cuida mais da parte burocrática, administrativa, ele não se envolve muito com a parte pedagógica. Nós temos um papel de um gestor não muito ativo, às vezes até uma figura mesmo que se esconde, não aparece muito.

Todavia, o docente deve entender que o estudante é o elemento com o qual atua profissionalmente, e ele não pode ser prejudicado por falta de estímulo do diretor.

\section{PRINCÍPIOS FUNDAMENTAIS NA GESTÃO ESCOLAR}

Os docentes compreendem a gestão escolar como processo de participação democrática de toda a comunidade (ARAÚJO, 2013; PARO, 2010; RIBEIRO, 2007), uma vez que os princípios democráticos que sustentam as ações do diretor são evidenciados, na concepção dos docentes, conforme discurso a seguir:

Excerto - DSC7: Comprometimento, presença, [...], liderança. As regras são princípios. Ética, equidade, respeito mútuo e solidariedade comprometida com o humano. [...] percebo comprometimento, princípios humanos bastante aflorados e organização. Organização, comprometimento, na verdade, valores, porque além de trabalhar com a parte financeira trabalha com sonhos, com anseios tanto de funcionários, quanto das pessoas que buscam um algo a mais aqui na instituição. A união, desde o diretor até os faxineiros tem que ter uma união concisa, que haja uma gestão bem democrática, uma gestão escolar muito bem planejada. [...]. Iniciativa no sentido de não estar preso apenas ao cumprimento do estritamente necessário burocrático, mas iniciativa para buscar mais, para abrir portas, criar mais oportunidades para que a própria escola cresça.

Mas em contrapartida, além dos princípios apontados no excerto acima, foram apontados princípios traduzidos no exercício autoritário do poder:

Excerto - DSC8: O burocrático, rituais para determinados procedimentos para que a rotina toda funcione. [...] pulso firme. É o trabalho em equipe, nós temos problemas de níveis hierárquicos e de burocracia que é um entrave, justamente ter essa noção. [...]. A gestão se preocupa mais com a questão política, no sentido partidário.

São necessários regras, rotinas e procedimentos na escola, mas devem ser determinados como consequência das ações coletivas e não impostos. A imposição gera o autoritarismo, enquanto a concordância livre e consciente das partes envolvidas leva à autoridade democrática (PARO, 2010). 


\section{DESAFIOS DA GESTÃO ESCOLAR NA INSTITUIÇÃO INVESTIGADA}

Os temas como falta de comprometimento com as atividades políticos educacionais, participação e evasão escolar, elencados pelos docentes entrevistados nesta pesquisa apostam no diretor para o sucesso da instituição, lembrando que gestão escolar é função do diretor, que pode ser resultado de uma participação democrática da comunidade ou impositiva, sem a participação da comunidade escolar. Todavia, percebe-se que não ocorre uma participação efetiva por parte dos docentes, assim como existe falta comprometimento com as atividades políticas e educacionais, segundo o discurso abaixo:

Excerto - DSC10: Principalmente o que eu não sinto aqui pra motivar o corpo não só docente, mas administrativo de certo fazer com que nós sejamos uma unidade de fato sabe, são pessoas fazendo cada um uma coisa desconexa, sem um interesse comum, entendeu de prospectar o nome da instituição. Trabalhar em conjunto acho que tudo vai progredir, caso contrário não tem essa progressão.

A gestão da escola precisa chamar para si a responsabilidade e participação, de todos os envolvidos, pelo desenvolvimento das atividades e consequentemente da escola, de maneira a se buscar certa autonomia (DE RÉ, 2011). E para isso os discursos apontam:

Excerto - DSC10: [...] o diretor precisa também ser um ser político, no sentido, de estar bem relacionado com as autoridades locais, com o empresariado local para firmar parcerias que possibilitem um melhor desenvolvimento das condições da própria escola, para que os estudantes tenham oportunidade de participar de mais eventos ligados ao que eles estão estudando. Maior penetração na comunidade, nós somos muito pouco conhecidos ainda, no meio local e regional.

Nesse contexto, o diretor deve exercer um trabalho importante, promover a participação e orientar os envolvidos no desenvolvimento das ações pedagógicas em todos os âmbitos. Principalmente quando esses desafios produzem resultados que envolvem a evasão escolar, é necessária a participação efetiva da comunidade para lidar com esta questão e discutir sobre o tema. Conforme se evidencia no discurso abaixo.

Excerto - DSC13: O maior desafio seria propor debates para fazer a comunidade refletir o quão é importante eles participarem não só apontando problemas, mas propondo sugestões, estratégias para melhorar, principalmente a questão da evasão. Quando que realmente nós vamos discutir propor ações para solucionar esse problema da evasão e da defasagem? O combate à evasão escolar. Controle de evasão, estruturar melhor o campus, divulgação do campus, fazer parcerias, dar visibilidade ao campus.

Portanto, os desafios devem ser encarados como oportunidade em ação, que move a comunidade escolar em busca da construção de uma gestão escolar voltada para atender aos princípios democráticos de participação.

\section{CONSIDERAÇÕES POSSÍVEIS}

É possível identificar que a gestão escolar é compreendida pelos docentes a partir de uma concepção que contempla seu aspecto administrativo e pedagógico. A superação dos desafios a 
serem enfrentados pelos docentes será a força norteadora, pois não tem outro lugar de emergir, a não ser pelo querer dos sujeitos e envolvimento de toda a comunidade escolar.

\section{REFERÊNCIAS}

ABDIAN, G. Z.; OLIVEIRA, M. E. N.; JESUS, G. de. Função do diretor na escola pública paulista: mudanças e permanências. Educação \& Realidade, Porto Alegre, v. 38, n. 3, p. 977-998, 2013, https://doi.org/10.1590/S2175-62362013000300015.

ARAÚJO, M. S. V. de. Elementos constituintes de aprendizagem para uma gestão escolar aprendente no Instituto Federal de Educação, Ciência e Tecnologia da Paraíba - Campus Cabedelo. 2013. Dissertação (Mestrado em Gestão) - Universidade Federal da Paraíba, João Pessoa - PB.

ASSUNÇÃO, M. L. V. da. Organização do trabalho escolar e atuação do administrador-escolar. 2004. Dissertação (Mestrado em Educação) - Universidade Federal de São Carlos, São Carlos - SP. BRASIL. Lei no 9.394, de 20 de dezembro de 1996. Estabelece as diretrizes e bases da educação nacional. Diário Oficial da União, Brasília, DF.

DE RÉ, C. A. T. O fenômeno da liderança em escolas públicas de ensino médio do Rio Grande do Sul. 2011. Tese (Doutorado em Engenharia da Produção) - Universidade Federal de Santa Catarina, Florianópolis - SC.

FORMIGA, M. das G. F. O administrativo e o pedagógico na gestão escolar. 2007. Dissertação (Mestrado em Educação). Faculdade de Educação e Letras, Universidade Metodista de São Paulo, São Bernardo do Campo - SP.

HOJAS, V. F. Concurso público para diretor na escola estadual paulista: expectativas dos órgãos centrais do ensino e concepções de diretores. Educação em Revista, Belo Horizonte, v. 31, n. 2, p. 309-326, 2015, https://doi.org/10.1590/0102-4698132942.

IGREJA, M. A. F. O diretor de Escola Pública: que profissional é este? 2008. Dissertação (Mestrado em Educação). Faculdade de Educação e Letras, Universidade Metodista de São Paulo, São Bernardo do Campo - SP.

LEFEVRE, A. M. C.; CRESTANA, M. F.; CORNETTA, V. K. A utilização da metodologia do discurso do sujeito coletivo na avaliação qualitativa dos cursos de especialização "Capacitação e Desenvolvimento de Recursos Humanos em Saúde-CADRHU", São Paulo - 2002. Saúde Sociedade, São Paulo, v. 12, n. 2, 2003.

PARO, V. H. A educação, a política e a administração: reflexões sobre a prática do diretor de escola. Educação e Pesquisa, São Paulo, v. 36, n. 3, p. 763-778, 2010, https://doi.org/10.1590/S1517$\underline{97022010000300008 .}$.

RIBEIRO, A. A gestão democrática do projeto político-pedagógico na escola pública de educação básica. 2007. Dissertação (Mestrado em Educação) - Pontifícia Universidade Católica do Paraná, Curitiba - PR.

SILVA, C. L. da; LEME, M. I. da S. O papel do diretor escolar na implantação de uma cultura educacional inclusiva. Psicologia: Ciência e Profissão, Brasília, v. 29, n. 3, p. 494-511, 2009, https://doi.org/10.1590/S1414-98932009000300006 
SOUZA, A.; GOUVEIA, A. B. Diretores de escolas públicas: aspectos do trabalho docente. Educar em Revista, Curitiba, n. spe1, p. 173-190, 2010. 